\title{
Influence of nickel citrate in flame retardant thermoplastic polyurethane elastomer composites based on ammonium polyphosphate
}

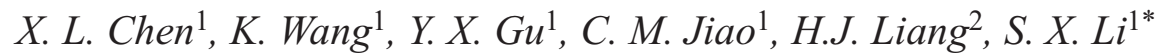 \\ ${ }^{1}$ College of Environment and Safety Engineering, Qingdao University of Science and Technology, Qingdao, 266042 \\ Shandong, P R China \\ ${ }^{2}$ College of Foreign Languages, Qingdao University of Science and Technology, Qingdao, 266042 Shandong, P R China
}

Received 19 July 2020; accepted in revised form 15 October 2020

\begin{abstract}
In this work, nickel citrate (NC) was combined with ammonium polyphosphate (APP) to improve the flame retardance of thermoplastic polyurethane (TPU). And, the influence of nickel citrate on the flame retardance of TPU/APP composites was investigated by cone calorimeter test (CCT), thermogravimetric analysis/infrared spectrometry (TG-IR), scanning electron microscope (SEM), gas chromatography/mass spectrometry (GC-Ms), and X-ray photoelectron spectrometer (XPS), respectively. It has been found the combination of NC and APP improved the flame retardancy and reduced the total heat release (THR) of TPU composites. The THR value of TPU/APP/ $\mathrm{NC}_{0.5}$ was reduced by $20.7 \%$ at $750 \mathrm{~s}$ compared with that of TPU/APP. The flame retardancy of TPU composites and the graphitization degree of char residue from TPU composites were improved by the combination of both NC and APP. This work provided a new way to improve the flame retardancy of polymer composites.
\end{abstract}

Keywords: polymer composites, flame retardancy, thermoplastic polyurethane elastomer, nickel citrate, ammonium polyphosphate

\section{Introduction}

As one of the most generic engineering thermoplastics, thermoplastic polyurethane (TPU) had been widely used in many fields such as wires, cables, automobiles, tubes, and adhesives due to its high tensile strength and abrasion resistance [1-3]. However, the wide applications of TPU had been limited by its high flammability. In particular, abundant toxic gases were released during combustion, including carbon monoxide and HCN [4], which led to a serious threat to human safety [5]. Therefore, the flame retardancy of TPU has to be improved to prolong its service life in various harsh environments.

Many methods had been used to improve the flame retardancy of TPU $[6,7]$. Much attention has been paid to halogen-free flame retardants in recent decades [8]. Intumescent flame retardants (IFR) have attracted wide attention due to its high flame retardant efficiency and environmental friendliness compared with halogen-containing flame retardants. There are three main substances in a common IFR system: acid source, char-forming agent, and a blowing agent $[9,10]$. As an efficient acid source and blowing agent, ammonium polyphosphate (APP) has been widely applied in TPU composites since its high phosphorus content ( $31 \mathrm{wt} \%)$ and the formation of a fluffy protective char layer $[9,11]$. However, the mechanical properties of TPU composites would deteriorate when a high loading of APP was added [12, 13]. It has been reported some synergisms can be used in TPU/APP 
composites to enhance the flame retardant efficiency and mechanical properties [14].

It has been reported that transition metal compounds can promote the carbonization of polymers during the combustion $[15,16]$, it was most effective when they were combined with other flame retardants as well as in small amounts [17]. The metal ions were coordinated to the molecule of TPU to make it in a condensed-phase [18]. Furthermore, it was found that nickel compounds had the function of catalytic carbonization and contributed to the flame retardancy of polymer composites $[19,20]$. NaNiP can significantly improve the flame retardancy of TPU composites by promoting TPU to form char residues with stable structures and make the LOI value increase to $32 \%$ [19]. The addition of $3.0 \mathrm{wt} \%$ of Salen-DPCP$\mathrm{Ni}$ can reduce the peak value of the heat release rate from $1495 \mathrm{~kW} / \mathrm{m}^{2}$ for neat TPU to $690 \mathrm{~kW} / \mathrm{m}^{2}$ [21]. Compared with pure TPU, the value of total smoke production TPU/rGO-Salen-Ni1.5 was reduced by $28 \%$ [20]. In addition, the organic nickel complexes, such as nickel citrate (NC), might be an excellent precursor for preparing metal nickel catalysts with high dispersion polymer resin [22]. However, there was no research about the influence of nickel citrate on the flame retardancy of polymer composites. Considering the different flame retardant mechanisms between APP and nickel compounds, it was expected that the combination of APP and NC would improve the flame retardancy of TPU composites.

In this work, NC was incorporated into TPU with APP to prepare TPU/APP/NC composites. Here, the flame retardant performance and thermal stability of TPU composites were investigated using different measurements, including CCT, TG-IR, SEM, GC-Ms, XPS, and LRS.

\section{Experimental}

\subsection{Materials}

Thermoplastic polyurethane (TPU, $9380 \mathrm{~A}$ ) was purchased from Covestro Polymers Co. Ltd (Shenzhen, China). Ammonium polyphosphate (APP, 300 meshes) was obtained from Jinan Taixing Fine Chemical Co. Ltd (Jinan, China). Citric acid (CA, purity $\geq 99.5 \%$ ) was supplied by Tianjin Beilian Fine Chemical Co. Ltd (Tianjin, China). Nickel acetate (purity $\geq 98.0 \%$ ) was purchased from Shanghai Shanpu Chemical Co. Ltd (Shanghai, China).

\subsection{Preparation of nickel citrate}

The nickel citrate (NC) was prepared by the following procedure. The nickel acetate tetrahydrate $\left(\mathrm{Ni}\left(\mathrm{CH}_{3} \mathrm{COO}\right)_{2} \cdot 4 \mathrm{H}_{2} \mathrm{O}, 0.03 \mathrm{~mol}\right)$ was dissolved into deionized water $(80 \mathrm{ml})$, and $\mathrm{CA}\left(\mathrm{C}_{6} \mathrm{H}_{8} \mathrm{O}_{7}, 0.036 \mathrm{~mol}\right)$ was dissolved into deionized water $(20 \mathrm{ml})$. Then, the nickel acetate solution was added to the CA solution slowly with stirring to obtain a green solution. And the green solution was aged at $70^{\circ} \mathrm{C}$ in a water bath until the green sol-gel appeared. The product was dried under $80^{\circ} \mathrm{C}$ for 24 hours in a vacuum oven. Finally, the light green NC powder was obtained.

\subsection{Preparation of flame retardant TPU composites}

TPU was dried at $60^{\circ} \mathrm{C}$ for $3 \mathrm{~h}$ in a vacuum oven, then mixed with both APP and $\mathrm{NC}$ with different weight ratios in the internal mixer. Then the blends were put into the tablet machine (with the size of $100 \times 100 \times$ $3 \mathrm{~mm}^{3}$ ) after mixed from the internal mixer. Five samples were prepared and named as TPU, TPU/APP, TPU/APP/ $/ \mathrm{NC}_{0.125}, \mathrm{TPU} / \mathrm{APP} / \mathrm{NC}_{0.25}, \mathrm{TPU} / \mathrm{APP} /$ $\mathrm{NC}_{0.5}$. The formulation of TPU composites was showed in Table 1.

\subsection{Measurements}

The morphological characteristics were investigated by scanning electron microscope (SEM, SU8000 $15.0 \mathrm{kV}$ ) with energy dispersive X-ray spectrometry (EDX). Before the tests, the specimens were sputtered with a thin gold coating to avoid electrostatic charging.

The thermal decomposition performance of TPU composites was tested by thermogravimetric analysis/ infrared spectrometry (TG-IR). TG-IR was performed

Table 1. Formulations, LOI and UL-94 results of flame retardant TPU composites.

\begin{tabular}{|c|c|c|c|c|c|}
\hline Samples & $\begin{array}{c}\text { TPU } \\
{[w t \%]}\end{array}$ & $\begin{array}{c}\text { APP } \\
{[w t \%]}\end{array}$ & $\begin{array}{c}\mathrm{NC} \\
{[\mathrm{wt} \%]}\end{array}$ & $\begin{array}{c}\text { LOI } \\
{[w t \%]}\end{array}$ & UL-94 \\
\hline TPU & 100.000 & 0 & 0 & 21.0 & NR \\
\hline TPU/APP & 92.000 & 8.000 & 0 & 26.5 & $\mathrm{~V}-1$ \\
\hline TPU/APP/NC 0.125 & 92.000 & 7.875 & 0.125 & 26.5 & $\mathrm{~V}-0$ \\
\hline TPU/APP/NC 0.25 & 92.000 & 7.750 & 0.250 & 26.5 & V-0 \\
\hline TPU/APP/NC ${ }_{0.5}$ & 92.000 & 7.500 & 0.500 & 27.0 & $\mathrm{~V}-1$ \\
\hline
\end{tabular}


on a DT-50 (Setaram, France) instrument that was interfaced with an FTIR spectrometer (IR Affinity-1, 170SX) (Shimadzu, Japan). There were about $10 \mathrm{mg}$ of samples placed in an alumina crucible. The heating rate was set as $10^{\circ} \mathrm{C} / \mathrm{min}$ (nitrogen atmosphere, the flow rate of $60 \mathrm{ml} / \mathrm{min}$ ), and the wavenumber range was set from 4000 to $400 \mathrm{~cm}^{-1}$.

The X-ray diffraction (XRD) was measured by D-MAX 2500/PC (Rigaku, Japan), and the data were collected over a $2 \theta$ range from 5 to $80^{\circ}$.

The combustion performance was tested by the cone calorimeter instrument (Fire Testing Technology, UK) according to ISO-5660 standard procedures. Each sample with dimensions of $100 \times 100 \times 3 \mathrm{~mm}^{3}$ was put in aluminum foil and exposed to an external heat flux of $35 \mathrm{~kW} / \mathrm{m}^{2}$.

The limiting oxygen index (LOI) test was conducted on a ZR-01 oxygen index meter (Qingdao Shanfang Instrument Co., Ltd.) according to the standard oxygen index test (ASTM D2863). The samples used were of dimensions $100 \times 6.5 \times 3 \mathrm{~mm}^{3}$, and five samples were studied in the LOI test.

The UL-94 level was tested on a CZF-3 instrument (Jiangning Analysis Instrument Co., Ltd.), according to ASTMD 380. The dimensions of samples were $100 \times 13 \times 3 \mathrm{~mm}^{3}$, and three samples were carried out in the UL-94 test.

The pyrolysis products of TPU composites were analyzed by gas chromatography/mass spectrometry (GC-Ms, QP2010 Ultra, Shimadzu, Japan). The chromatographic separation was performed using the Rxi-5sil Ms capillary column with high-purity helium as the carrier gas, the mass of samples required was about $3 \sim 5 \mathrm{mg}$. The temperature of chromatographic column was gradually increased, maintained at $30^{\circ} \mathrm{C}$ for 2 minutes, raised to $130{ }^{\circ} \mathrm{C}$ at a heating rate of $10 \mathrm{~K} / \mathrm{min}$ and kept for 2 minutes, then raised to $180^{\circ} \mathrm{C}$ at a heating rate of $12 \mathrm{~K} / \mathrm{min}$ and held for 2 minutes. At last, it was raised to $280^{\circ} \mathrm{C}$ at a heating rate of $7 \mathrm{~K} / \mathrm{min}$ and maintained for 10 minutes.

The laser Raman spectroscopy (LRS) test for the char residue was conducted on a Horiba Scientific LabRam HR Evolution at ambient temperature. A $514 \mathrm{~nm}$ laser had an output optical power of about $1 \mathrm{~mW}$ (about $1 \mathrm{~mW}$ after the laser was attenuated by about $1 \%$ ) and an integration time of $200 \mathrm{~s}$, the scanning range was $5000-40 \mathrm{~cm}^{-1}$.

The X-ray photoelectron spectrometer (XPS) was tested by Thermo Fischer, ESCALAB 250XI (US). The analysis chamber vacuum degree was $4 \cdot 10^{-9} \mathrm{mbar}$, the excitation source was Al ka ray $(h v=1486.6 \mathrm{eV})$, the working voltage was $14.6 \mathrm{kV}$, the filament current was $13.5 \mathrm{~mA}$, and the signal accumulation of 20 cycles was performed. Passing-Energy was $20 \mathrm{eV}$, the step size was $0.1 \mathrm{eV}$, and $C_{1 \mathrm{~s}}=284.8 \mathrm{eV}$ combined energy as the energy standard for charge correction.

\section{Results and discussion}

\subsection{Characterization of $\mathrm{NC}$}

The SEM images of NC were shown in Figure 1a, $1 \mathrm{~b}$, the morphology of $\mathrm{NC}$ particles was irregular with the size from 1 to $5 \mu \mathrm{m}$. NC was also tested via EDX, and the results were shown in Figure 1b. The weight percent of $\mathrm{C}, \mathrm{O}$, and $\mathrm{Ni}$ on the surface were about $3.92,8.49$, and $87.59 \%$, respectively. The thermal decomposition behavior of $\mathrm{NC}$ was further characterized using the TG test in $\mathrm{N}_{2}$ (Figure 1c), and the detailed data were shown in Table 2. $T_{5 \%}$ and $T_{\max }$ were defined as the temperatures at the initial and the maximum weight loss rate, respectively. The initial decomposition temperature of CA was $207.6^{\circ} \mathrm{C}$ while that of $\mathrm{NC}$ was about $6^{\circ} \mathrm{C}$ higher than that of CA. This implies that $\mathrm{NC}$ does not decompose in the preparation process of TPU composites. The maximum decomposition temperature of CA appeared at $252.3^{\circ} \mathrm{C}$, while that of $\mathrm{NC}$ was $266.8^{\circ} \mathrm{C}$, which was about $15^{\circ} \mathrm{C}$ higher than $\mathrm{CA}$. Moreover, the char residue of $\mathrm{CA}$ and $\mathrm{NC}$ at $685^{\circ} \mathrm{C}$ was 12.1 and $49.7 \mathrm{wt} \%$, respectively.

Figure 1d showed the XRD patterns of the products obtained after $\mathrm{NC}$ was calcined for $2 \mathrm{~h}$ at 300 and $600^{\circ} \mathrm{C}$, respectively. The XRD pattern for the residue obtained at $300^{\circ} \mathrm{C}$ showed the emergence of reflections appeared at $2 \theta=37.2,43.3,62.8,75.3$ and $79.3^{\circ}$ [23], which was assigned to $\mathrm{NiO}$ (PDF 71-1179). However, besides the $\mathrm{NiO}$ (PDF 71-1179) appeared at $2 \theta=37.2,43.3,62.8,75.1$ and $78.9^{\circ}$, the XRD pattern for the residue obtained at $600^{\circ} \mathrm{C}$ also showed the emergence of reflections appeared at $2 \theta=44.5$, 51.8 and $76.3^{\circ}$ assigned to Ni (PDF 87-0712) [24]. These results indicated that the decomposition product of $\mathrm{NC}$ at $600^{\circ} \mathrm{C}$ was $\mathrm{NiO}-\mathrm{Ni}$ blends, and most of them were $\mathrm{NiO}$ [23]. It can be speculated that $\mathrm{NiO}$ from the decomposition of $\mathrm{NC}$ played a synergistic flame retardant role with APP at the initial combustion process of TPU/APP/NC composites. And, when the temperature was raised to high temperature, both $\mathrm{NiO}$ and Ni played as flame retardant synergism in the above system. 


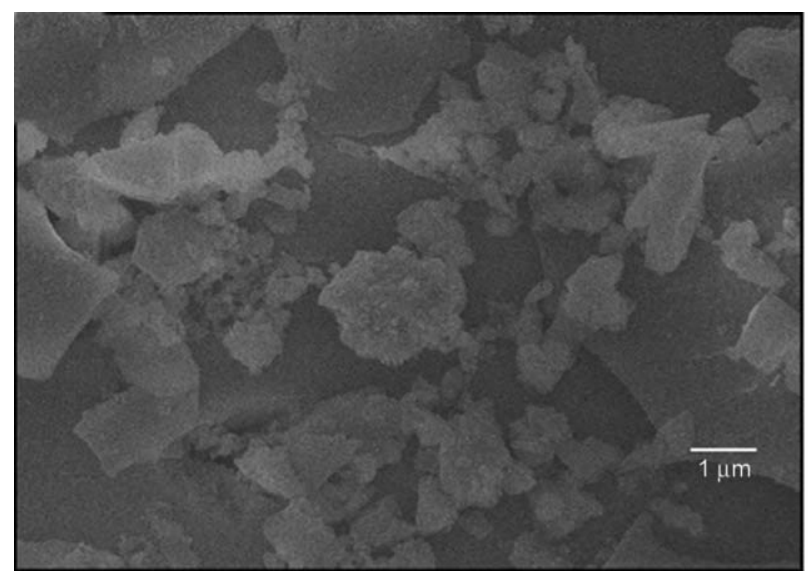

a)

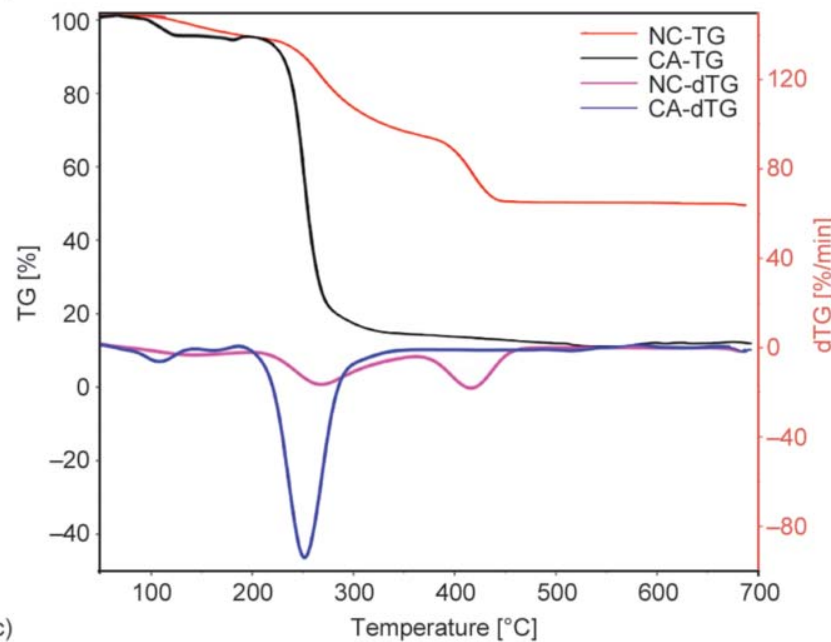

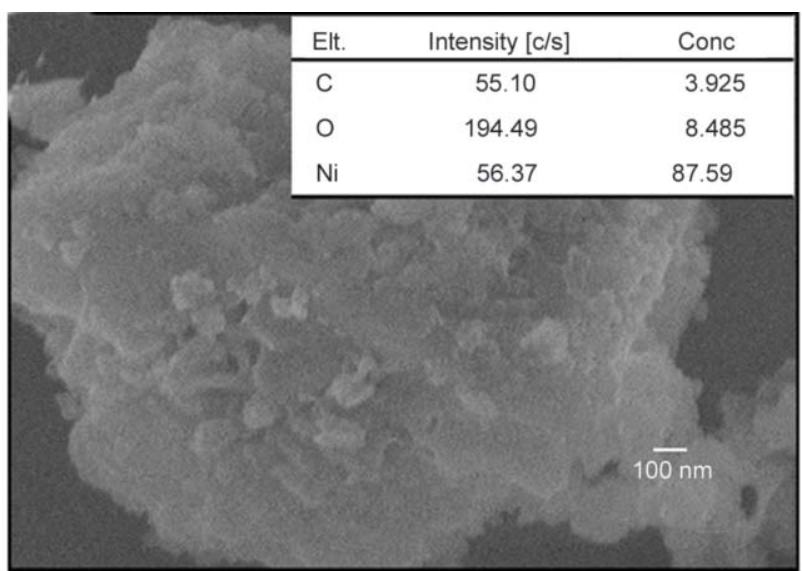

b)

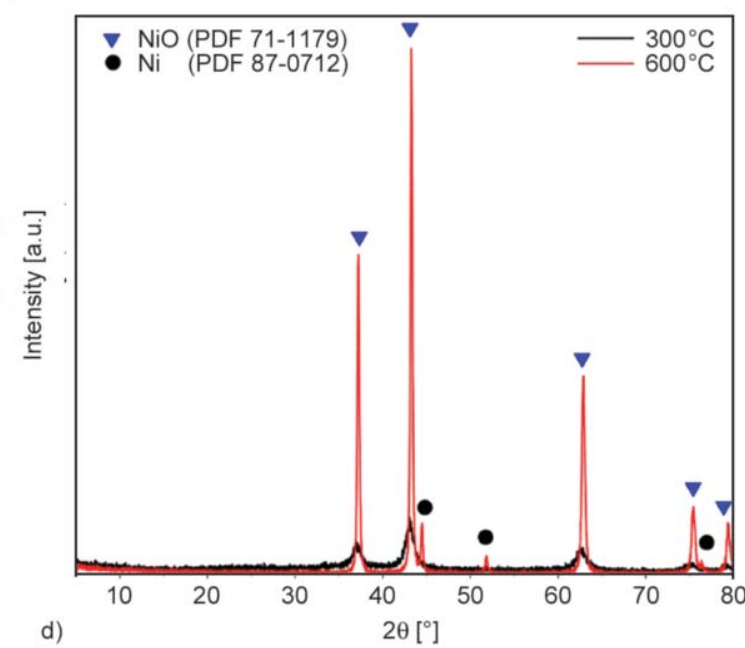

Figure 1. SEM images and EDX results of $\mathrm{NC}(\mathrm{a}, \mathrm{b}), \mathrm{TG}$ and $\mathrm{dTG}(\mathrm{c})$ curves of $\mathrm{NC}$ and $\mathrm{CA}$ under $\mathrm{N}_{2}$ atmosphere, XRD patterns (d) of the products calcined for $2 \mathrm{~h}$ of $\mathrm{NC}$ at 300 and $600{ }^{\circ} \mathrm{C}$.

Table 2. Thermogravimetric data of $\mathrm{CA}$ and $\mathrm{NC}$ in $\mathrm{N}_{2}$ atmosphere.

\begin{tabular}{|l|c|c|c|}
\hline Samples & $\begin{array}{c}\boldsymbol{T}_{\mathbf{5} \%} \\
{\left[{ }^{\circ} \mathbf{C}\right]}\end{array}$ & $\begin{array}{c}\boldsymbol{T}_{\max } \\
{\left[{ }^{\circ} \mathbf{C}\right]}\end{array}$ & $\begin{array}{c}\text { Char residue at } \mathbf{6 8 5}^{\circ} \mathbf{C} \\
{[\mathbf{w t} \% \mathbf{]}]}\end{array}$ \\
\hline $\mathrm{CA}$ & 207.6 & 252.3 & 12.1 \\
\hline $\mathrm{NC}$ & 213.8 & 266.8 & 49.7 \\
\hline
\end{tabular}

\subsection{Combustion performance of TPU composites}

$\mathrm{CCT}$ is one of the most effective measures to evaluate the fire performance of polymer composites [25-27]. The radiation power was set as $35 \mathrm{~kW} / \mathrm{m}^{2}$ to investigate the combustion behaviors of TPU composites.
The combustion performance parameters, including the time to ignition (TTI), time to end of flame (EOF), heat release rate (HRR), total heat release (THR), and residual mass were investigated. The detailed data of CCT results was showed in Table 3.

The HRR, THR, Mass, and CO curves of TPU composites were exhibited in Figure 2. As presented in Table 3, the peak HRR (PHRR) value of TPU was $1016.2 \mathrm{~kW} / \mathrm{m}^{2}$ while that of TPU/APP was $234.6 \mathrm{~kW} / \mathrm{m}^{2}$. In the case of the samples with $\mathrm{NC}$, it can be found NC could reduce the PHRR value of TPU composites effectively, and the PHRR value of TPU/APP/ $/ \mathrm{NC}_{0.5}$ was $182.3 \mathrm{~kW} / \mathrm{m}^{2}$, which was

Table 3. Combustion parameters of TPU composites obtained from CCT.

\begin{tabular}{|c|c|c|c|c|c|c|c|}
\hline Samples & $\begin{array}{c}\text { TTI } \\
{[\mathbf{s}]}\end{array}$ & $\begin{array}{c}\text { EOF } \\
{[s]}\end{array}$ & $\begin{array}{c}T_{\text {PHRR }} \\
{[\mathbf{s}]}\end{array}$ & $\begin{array}{c}\text { PHRR } \\
{\left[\mathrm{kW} / \mathbf{m}^{2}\right]}\end{array}$ & $\begin{array}{c}\text { THR } \\
{\left[\mathrm{MJ} / \mathrm{m}^{2}\right]}\end{array}$ & $\begin{array}{c}\text { FGI } \\
{\left[\mathrm{kW} /\left(\mathrm{m}^{2} \mathrm{~s}\right)\right]}\end{array}$ & $\begin{array}{c}\text { FPI } \\
\left.\left[\mathrm{m}^{2} \mathbf{s} / \mathbf{k W}\right)\right]\end{array}$ \\
\hline TPU & 106 & 471 & 281 & 1016.2 & 124.1 & 3.62 & 0.10 \\
\hline TPU/APP & 65 & 761 & 94 & 234.6 & 37.2 & 2.50 & 0.28 \\
\hline TPU/APP/NC ${ }_{0.125}$ & 59 & 1127 & 86 & 188.8 & 33.8 & 2.20 & 0.31 \\
\hline TPU/APP/NC $\mathrm{N}_{0.25}$ & 62 & 1947 & 87 & 191.3 & 35.5 & 2.20 & 0.32 \\
\hline TPU/APP/NC 0.5 & 53 & 1893 & 80 & 182.3 & 39.2 & 2.28 & 0.29 \\
\hline
\end{tabular}


reduced by $22.3 \%$ compared with that of TPU/APP. From Figure $2 \mathrm{~b}$ and Table 3 , it can be seen the THR value of pure TPU was $124.1 \mathrm{MJ} / \mathrm{m}^{2}$. And the THR value of TPU/APP was $37.2 \mathrm{MJ} / \mathrm{m}^{2}$, and that of TPU/APP/ $/ \mathrm{NC}_{0.125}$ was $33.8 \mathrm{MJ} / \mathrm{m}^{2}$, which was reduced by $9.1 \%$ compared with that of TPU/APP. The PHRR and THR values of the samples containing NC were lower than those of TPU/APP. The time required for the samples with $\mathrm{NC}$ to get the same THR value was much longer than that for the sample containing APP only, which further suggested that NC could effectively inhibit the heat release during the combustion process of TPU composite, thus furtherly improved the flame retardant performance of TPU composites.

Consequently, mass loss was also an important parameter for the anti-flaming and smoke suppression of polymer composites [28, 29]. And the mass loss curves of TPU composites were shown in Figure 2c. It can be seen that there was almost no char residue from pure TPU at the end of the combustion. Furthermore, pure TPU decomposed very rapidly in the
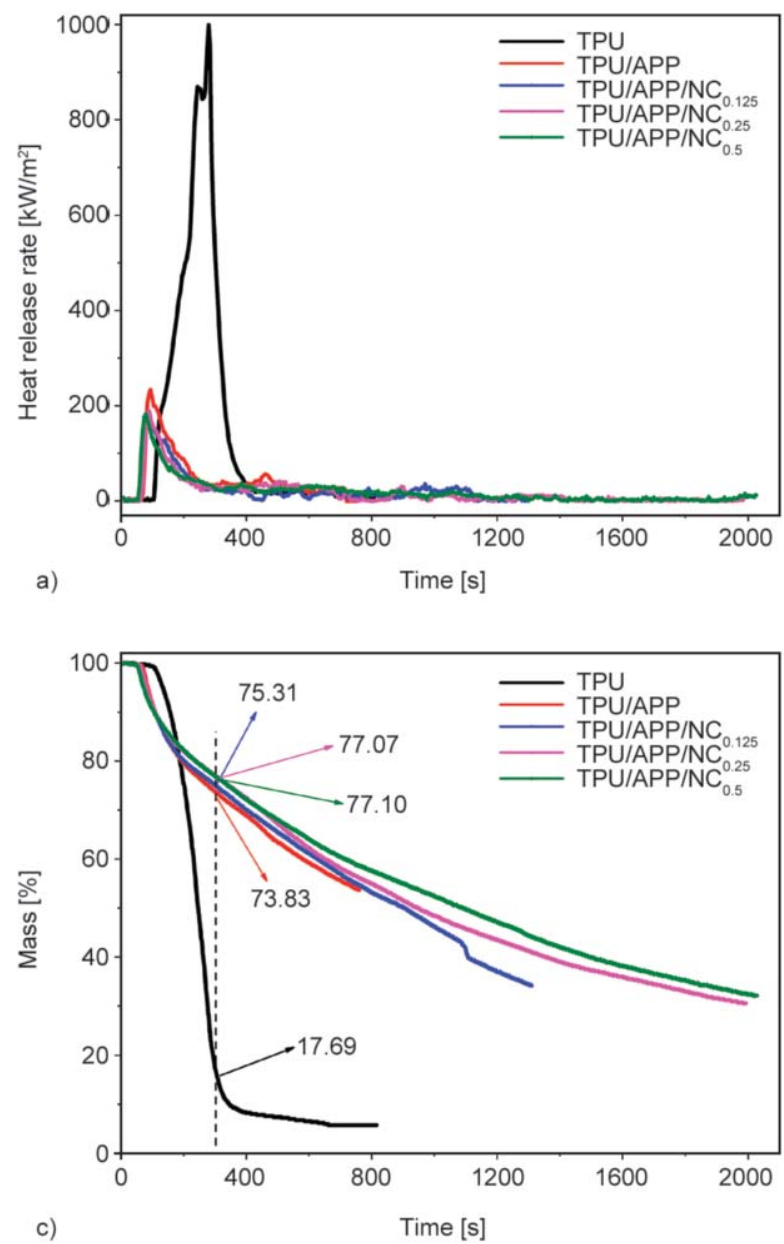

range of 160-300 s. And, the remaining mass of pure TPU was only $17.69 \%$ at $300 \mathrm{~s}$. However, there was about $73.83 \%$ remaining mass for the TPU/APP sample at $300 \mathrm{~s}$. For the samples with NC, the mass of char residues from TPU composites increased gradually with the increase of NC at $300 \mathrm{~s}$. In other words, there were fewer gas-phase products formed for the samples with NC. Therefore, NC improved the flame retardant performance of the composites through the carbonization process of TPU composites. The results of mass loss well corresponded to the results of the heat parameters. An intumescent char was formed on the surface of the samples during the combustion, which kept oxygen from diffusing into the underlying matrix or provided a low volatilization rate. The structure of the char residue also affected the release of smoke particles [30, 31].

For humans, it was important to reduce the release of smoke particles and toxic gases that were also fatal to humans in a real fire. Carbon monoxide is the main cause of death in a fire. The production rate curves of $\mathrm{CO}$ was shown in Figure 2d. It was obvious that a
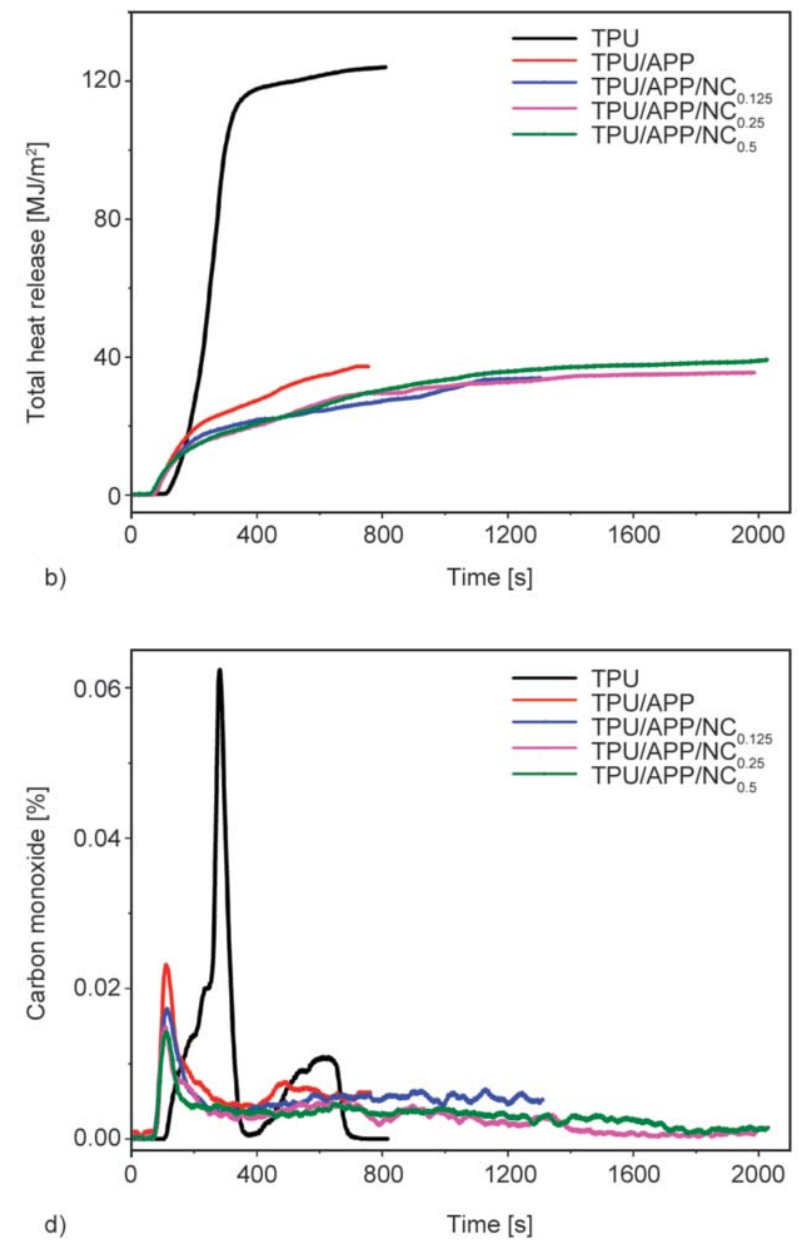

Figure 2. HRR (a), THR (b), Mass (c) and CO (d) curves of TPU composites. 
large number of $\mathrm{CO}$ was released during the combustion of pure TPU. The maximum production rate value of CO from pure TPU was $0.062 \%$, while that of TPU/APP was $0.023 \%$. For TPU/APP/ $\mathrm{NC}_{0.5}$ sample, the maximum production rate value of $\mathrm{CO}$ was $0.014 \%$, which was reduced by $39.1 \%$ compared with TPU/APP. This indicated NC significantly reduced the toxic substances.

In addition, to obtain further parameters of fire hazard, the fire performance index (FPI) and fire growth index (FGI) from the CCT data were calculated as the formula: FPI $=$ TTI/PHRR, FGI $=$ PHRR $/ T_{\text {PHRR }}$. The high FPI value and low FGI value represented high fire safety performance for flame retardant materials [32]. It is noted that TPU/APP/ $\mathrm{NC}_{0.25}$ possessed the highest FPI value and the lowest FGI value among all samples, indicating that it showed the best fire safety features.

Generally, the structure of the char residue layer has a certain influence on the thermal parameters and smoke parameters of TPU composites. The digital photographs (the top view and front view) of char residue from TPU composites were presented in
Figure 3. It was found that there was only a small amount of char residue layer with almost no expansion for the pure TPU sample. It can be seen APP in TPU/APP sample can make the char residue layer expand high with some large holes, and the structure of the char residue layer was uneven and not dense enough. In the case of the samples with $\mathrm{NC}$, it can be seen $\mathrm{NC}$ can further improve the structure of the char residue layer based on TPU/APP, including the expansion degree and compactness. For TPU/APP/ $\mathrm{NC}_{0.125}$ sample, there was an intact char layer formed with the higher expansion than that from TPU/APP sample. The most compact and densest char residue layer was obtained for TPU/APP/ $/ \mathrm{NC}_{0.5}$ in all samples. The SEM images and EDX of char residues for TPU composites after CCT were also showed in Figure 3. From Figure 3, it can be seen the outer surface of char residue from pure TPU was continuous with some pores that might be formed by gas generation during the decomposition of pure TPU. Compared with TPU, TPU/APP formed a compact char layer but still existed small holes in the surface of the residues. In addition, after the $0.5 \mathrm{wt} \% \mathrm{NC}$ was added, a tighter char

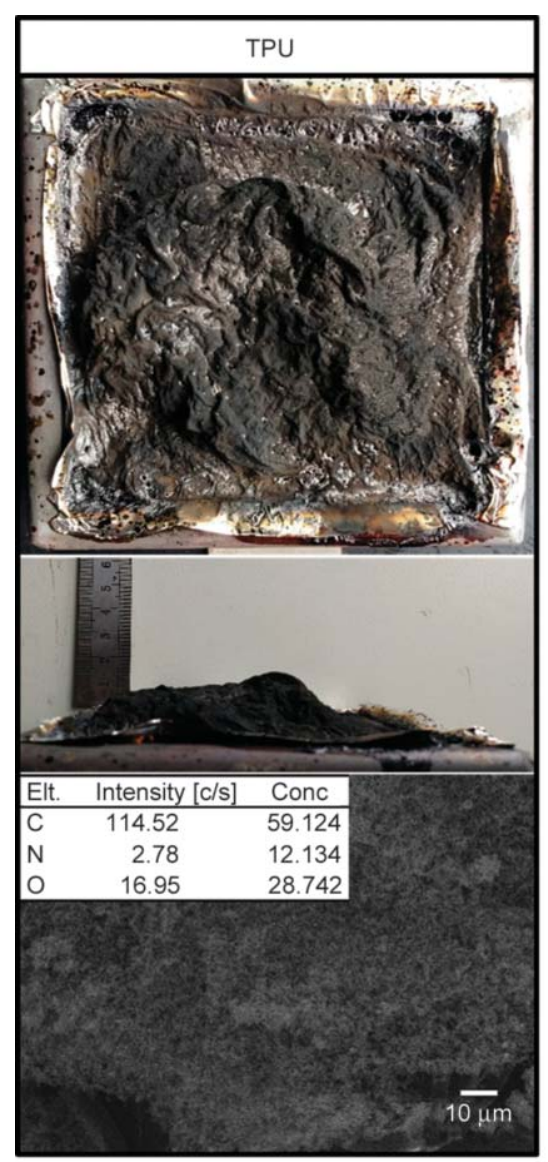

a)

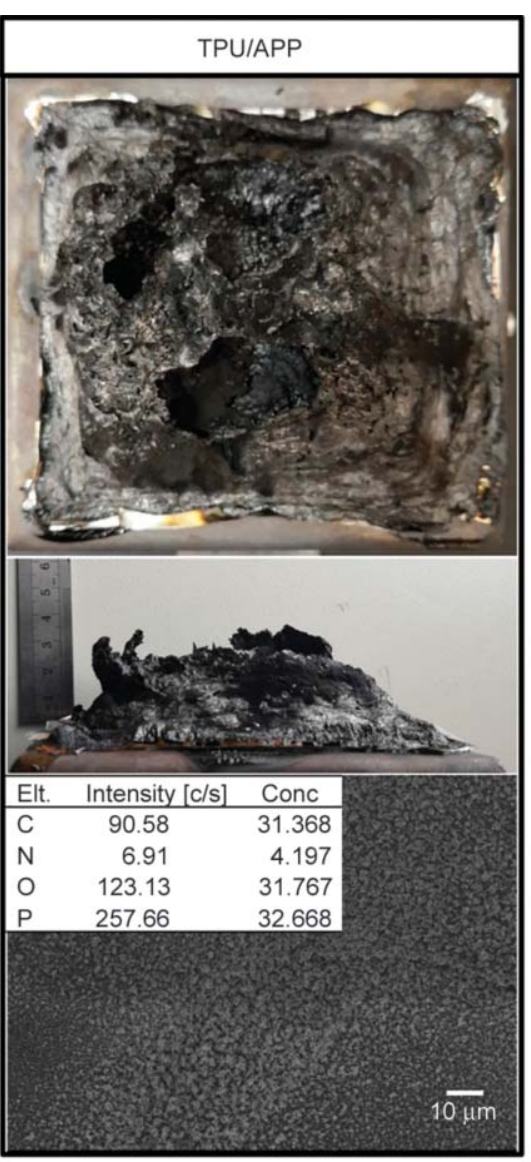

b)

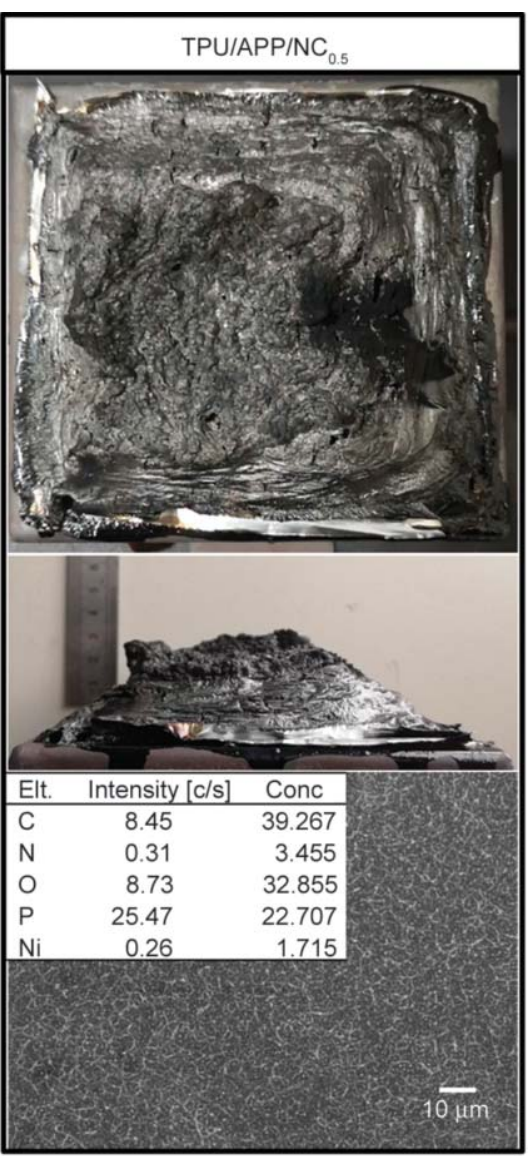

c)

Figure 3. Digital photographs images, SEM images and EDX results of char residue for TPU composites after CCT, TPU (a), TPU/APP (b), TPU/APP/NC 0.5 (c). 
residue layer was observed on the outer surface of TPU/APP/ $/ \mathrm{NC}_{0.5}$, which acted as a barrier to inhibit the transfer of heat and oxygen during the combustion [33]. The dense char residue layer formed from TPU/APP/ $\mathrm{NC}_{0.5}$ sample because of the combination of NC and APP in TPU. The elemental composition and content of the char residue layer were shown in Figure 3 . There were only $\mathrm{C}, \mathrm{N}$, and $\mathrm{O}$ elements detected from the pure TPU sample, and there were $\mathrm{C}$, $\mathrm{N}, \mathrm{O}$, and $\mathrm{P}$ elements detected from TPU/APP sample. However, for the TPU/APP/ $/ \mathrm{NC}_{0.5}$ sample, a new peak corresponding to nickel element was found except the peaks of $\mathrm{C}, \mathrm{N}, \mathrm{O}$, and $\mathrm{P}$ elements, indicating there were some nickel-containing substances in the char residue layer, which can greatly improve the flame retardancy of polymer composites [34]. The EDX results further indicated that the formation of the condensed phase might play a vital role during

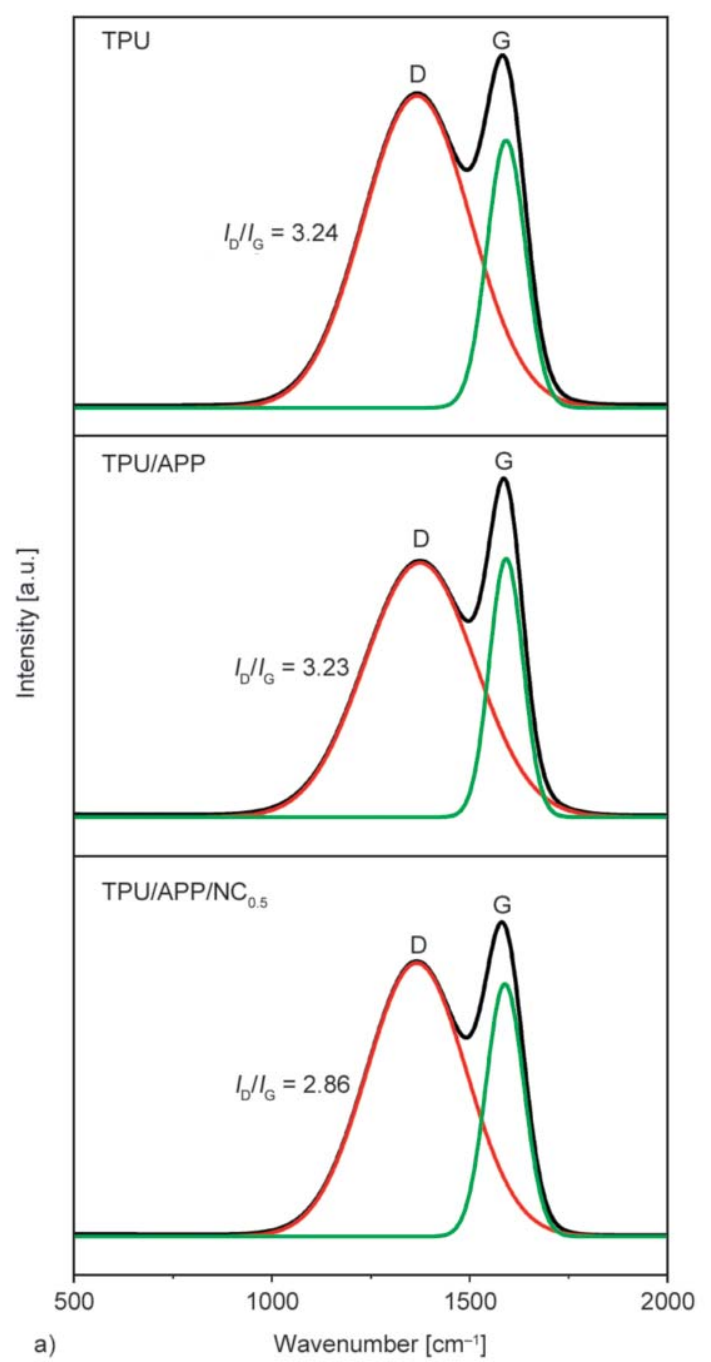

the combustion of TPU composites through the combination of ammonium APP and NC.

Moreover, the char residue layer after CCT were further characterized by LRS and XPS. And the LRS of char residues from TPU and its composites was given in Figure 4. It can be seen all spectra showed $\mathrm{D}$ and $\mathrm{G}$ band at about 1360 and $1590 \mathrm{~cm}^{-1}$ [35], respectively, attributing to the disorder of graphite crystals or glassy carbon and tensile vibration [36]. The graphitization degree of char residues was often estimated by the ratio of the integrated intensities of $D$ band to $\mathrm{G}$ band $\left(I_{\mathrm{D}} / I_{\mathrm{G}}\right)$. It was reported the low value of $I_{\mathrm{D}} / I_{\mathrm{G}}$ means a high degree of graphitization [37]. As shown in Figure 4 , the $I_{\mathrm{D}} / I_{\mathrm{G}}$ of the char residue from pure TPU was 3.24 , while $I_{\mathrm{D}} / I_{\mathrm{G}}$ values of the char residues from TPU/APP and TPU/APP/ $/ \mathrm{NC}_{0.5}$ were 3.23 and 2.86, respectively. The results showed that the degree of graphitization of the char residue
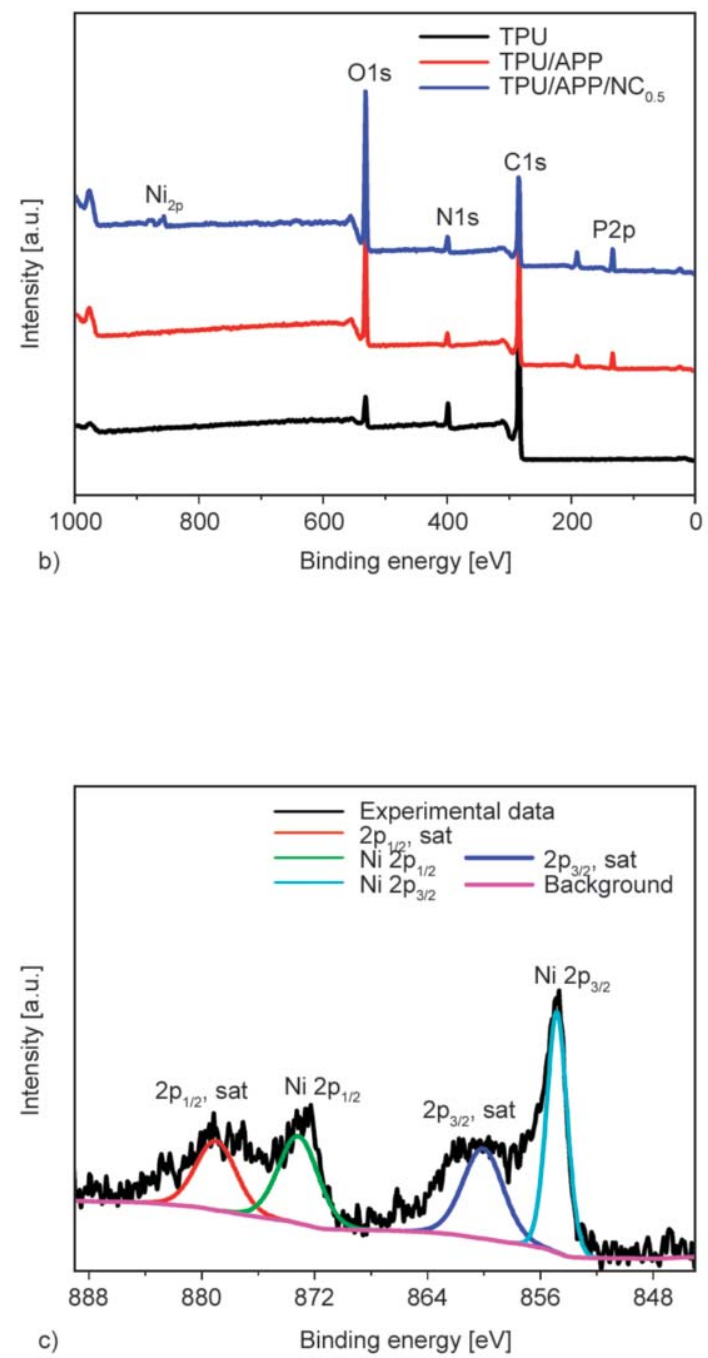

Figure 4. Raman spectra of the char residues after CCT of TPU composites (a), XPS spectra of the char residues after CCT of (b) TPU composites and deconvoluted XPS survey of (c) $\mathrm{Ni}_{2 p}$. 
from TPU/APP/ $\mathrm{NC}_{0.5}$ was the highest among all samples. The results showed that NC can significantly promote carbonization and graphitization. And, the formation of char residue layer was conducive to improve heat insulation and oxygen isolation [38], thus the flame retardancy of TPU composites had been enhanced.

The bonding among elements for the char residues from TPU composites after CCT were further confirmed using XPS [39]. The survey spectrum (Figure $4 \mathrm{~b}$ ) is good in accordance with Figure 3 . The highresolution of $\mathrm{Ni}_{2 \mathrm{p}}$ XPS spectrum for the TPU/APP/ $\mathrm{NC}_{0.5}$ sample was shown Figure $4 \mathrm{c}$. The two main peaks at 872.6 and $854.7 \mathrm{eV}$ corresponded to $\mathrm{Ni}_{2 p_{1 / 2}}$ and $\mathrm{Ni}_{2 \mathrm{p}_{3 / 2}}$, respectively $[23,40]$. Focusing on the $\mathrm{Ni}_{2 p_{3 / 2}}$ core-level spectra, there were two Ni species in Figure 4c. And, the binding energy values of 854.0 854.9 and $851.8-852.7 \mathrm{eV}$ were attributed to $\mathrm{NiO}$ and metal Ni, resepectively [23]. This result was corresponding to the $\mathrm{XRD}$ results in Figure 1, further indicating that the decomposition products of $\mathrm{NC}$ were $\mathrm{NiO}$ and $\mathrm{Ni}$.
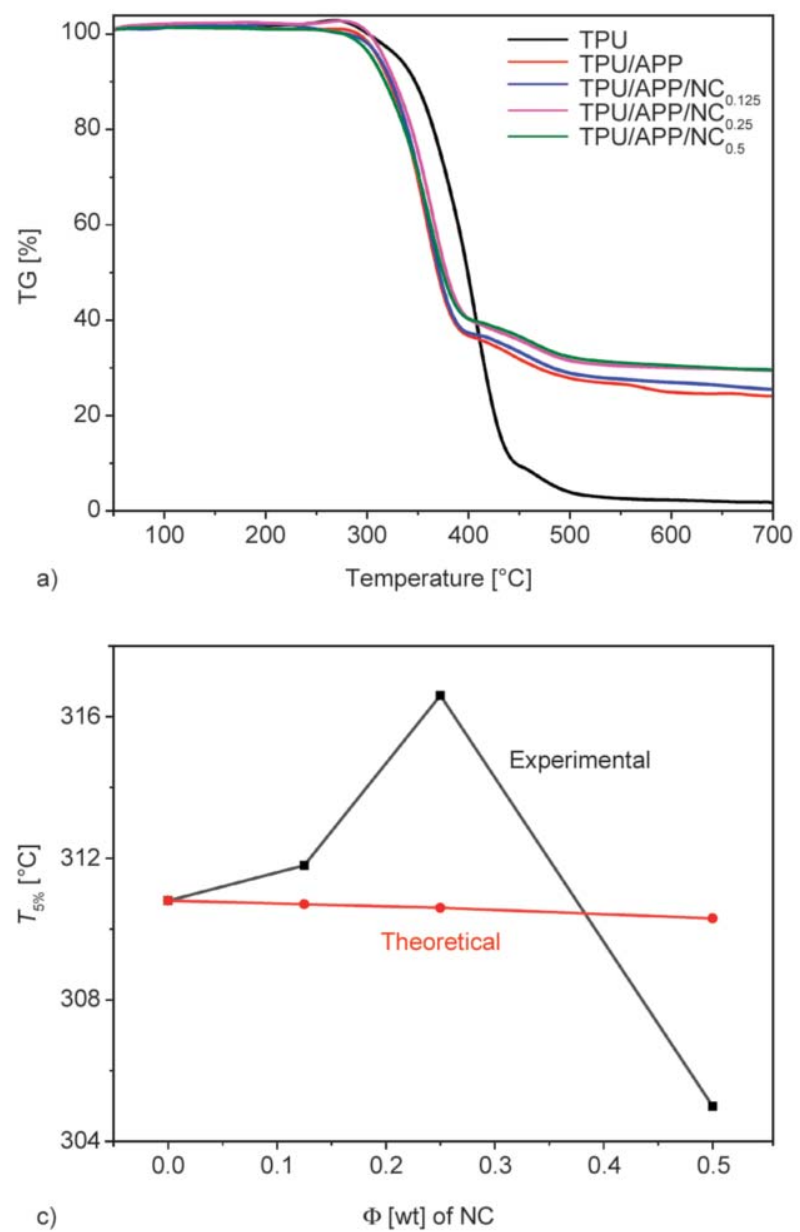

LOI and UL-94 tests were widely used to evaluate the flame retardancy of polymer composites [41]. The LOI values and UL-94 rating for all samples were shown in Table 1. The LOI value of pure TPU was only $21.0 \%$, and pure TPU did not pass the UL-94 test. The LOI value of TPU/APP increased to $26.5 \%$ with the addition of $8 \mathrm{wt} \%$ APP and the UL-94 rating of TPU/APP increased to V-1. Compared with TPU/ APP, the LOI value of both TPU/APP/ $\mathrm{NC}_{0.125}$ and TPU/APP/ $/ \mathrm{NC}_{0.25}$ were the same as $26.5 \%$ and the UL-94 rating of the above two samples was increased to $\mathrm{V}-0$. The $\mathrm{LOI}$ value of TPU/APP/ $\mathrm{NC}_{0.5}$ was increased to $27.0 \%$, and the UL-94 rating was reduced to V-1. It was reported that the UL-94 rating of TPU composites containing $19 \mathrm{wt} \%$ APP and $1 \mathrm{wt} \%$ NaNiP reached to V-1 [19]. The addition of NC increased the flame retardant efficiency of TPU/APP composites.

\subsection{Thermal performance of TPU composites}

The TG and dTG curves were shown in Figure 5, and the detailed data were summarized in Table 4. As
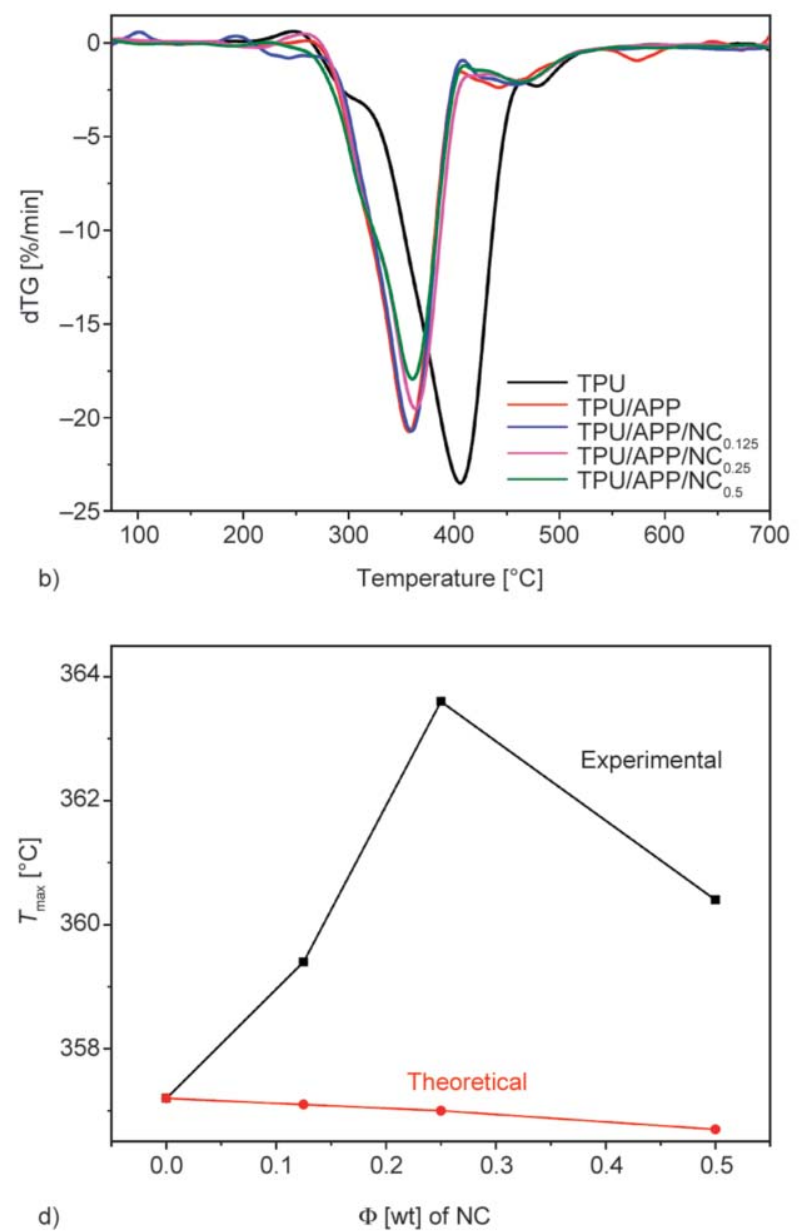

Figure 5. TG (a) and dTG (b) curves of TPU composites under $\mathrm{N}_{2}$ atmosphere and comparison of experimental values to theoretical values of degradation temperatures of TPU composites in $\mathrm{N}_{2}$ condition (c, d). 
Table 4. Thermogravimetric data of TPU and its composites under $\mathrm{N}_{2}$ atmosphere.

\begin{tabular}{|c|c|c|c|c|c|}
\hline Samples & $\begin{array}{l}T_{5 \%} \\
{\left[{ }^{\circ} \mathbf{C}\right]}\end{array}$ & $\begin{array}{l}T_{5 \%}^{\mathrm{cal}} \\
\left.{ }^{\circ} \mathrm{C}\right]\end{array}$ & $\begin{array}{l}T_{\max } \\
{\left[{ }^{\circ} \mathrm{C}\right]}\end{array}$ & $\begin{array}{c}T_{\max }^{\mathrm{cal}} \\
\left.{ }^{\circ} \mathbf{C}\right]\end{array}$ & $\begin{array}{c}\text { Char residue } \\
\text { at } 700{ }^{\circ} \mathrm{C} \\
{[w t \%]}\end{array}$ \\
\hline TPU & 331.4 & & 407.1 & & 1.7 \\
\hline TPU/APP & 310.8 & 310.8 & 357.2 & 357.2 & 24.2 \\
\hline TPU/APP/NC $\mathrm{N}_{0.125}$ & 311.8 & 310.7 & 359.4 & 357.1 & 25.5 \\
\hline TPU/APP/NC ${ }_{0.25}$ & 316.6 & 310.6 & 363.6 & 357.0 & 29.5 \\
\hline TPU/APP/NC ${ }_{0.5}$ & 305.0 & 310.3 & 360.4 & 356.7 & 29.6 \\
\hline
\end{tabular}

shown in Figure $5 \mathrm{a}, 5 \mathrm{~b}$ and Table $4, T_{5 \%}$ of TPU was $331.4^{\circ} \mathrm{C}$. For TPU/APP and TPU/APP/NC system, $T_{5 \%}$ was lower than that of TPU because the initial decomposition temperature of APP was lower than TPU. Moreover, the char residue of TPU was $1.7 \mathrm{wt} \%$ only at $700{ }^{\circ} \mathrm{C}$, while that of TPU/APP was $24.2 \mathrm{wt} \%$. And, the char residues of TPU/APP/ $\mathrm{NC}_{0.125}$, TPU/ $\mathrm{APP} / \mathrm{NC}_{0.25}$, and TPU/APP/ $\mathrm{NC}_{0.5}$ were $25.5,29.5$, and $29.6 \mathrm{wt} \%$, respectively. With the increase of $\mathrm{NC}$, the char residue of TPU/APP/NC composites was increasing gradually at $700^{\circ} \mathrm{C}$, indicating that $\mathrm{NC}$ increased the thermal stability of TPU/APP/NC composites at high temperatures. To further understand the effect of NC on the thermal stability of TPU composites, it was assumed that both $T_{5 \%}^{\mathrm{cal}}$ and $T_{\max }^{\mathrm{cal}}$ of TPU composites obey the linear mixing law, as shown in Equation (1) and (2) [42]:

$T_{5 \%}^{\mathrm{cal}}=T_{5 \%, \mathrm{TPU} / \mathrm{APP}} \cdot \Phi_{\mathrm{w}, \mathrm{TPU} / \mathrm{APP}}+T_{5 \%, \mathrm{NC}} \cdot \Phi_{\mathrm{w}, \mathrm{NC}}$

$T_{\max }^{\mathrm{cal}}=T_{\max , \mathrm{TPU} / \mathrm{APP}} \cdot \Phi_{\mathrm{w}, \mathrm{TPU} / \mathrm{APP}}+T_{\max , \mathrm{NC}} \cdot \Phi_{\mathrm{w}, \mathrm{NC}}$

where $T_{5 \%, \mathrm{TPU} / \mathrm{APP}}$ and $T_{5 \%, \mathrm{NC}}$ refer to the $T_{5 \%}$ of TPU/ APP and NC, respectively. $\Phi_{\mathrm{w}, \mathrm{TPU} / \mathrm{APP}}$ and $\Phi_{\mathrm{w}, \mathrm{NC}}$ represent the mass fraction of TPU/APP and NC, respectively. The same was applied to both $T_{\max , T P U / A P P}$ and $T_{\max , \mathrm{NC}}$. As shown in Figure $5 \mathrm{c}, 5 \mathrm{~d}$, all experimental values of both $T_{5 \%}$ and $T_{\max }$ were higher than the theoretical values except for TPU/APP/ $\mathrm{NC}_{0.5}$. The TPU/APP/ $/ \mathrm{NC}_{0.25}$ exhibited the largest differences between experimental and theoretical values, indicated that the addition of $0.25 \mathrm{wt} \% \mathrm{NC}$ possessed the best ratio in this formulation.

TG-IR was carried out under nitrogen, and the IR spectra under the maximum degradation rate were shown in Figure 6. TPU/APP and TPU/APP/NC had similar spectrum upon TPU, and these bands owned to functional group or component with characteristic bands. The bands of water $\left(3725 \mathrm{~cm}^{-1}\right),-\mathrm{CH}_{3}$ and $-\mathrm{CH}_{2}-\left(2974\right.$ and $\left.2855 \mathrm{~cm}^{-1}\right), \mathrm{CO}_{2}\left(2357 \mathrm{~cm}^{-1}\right)$,

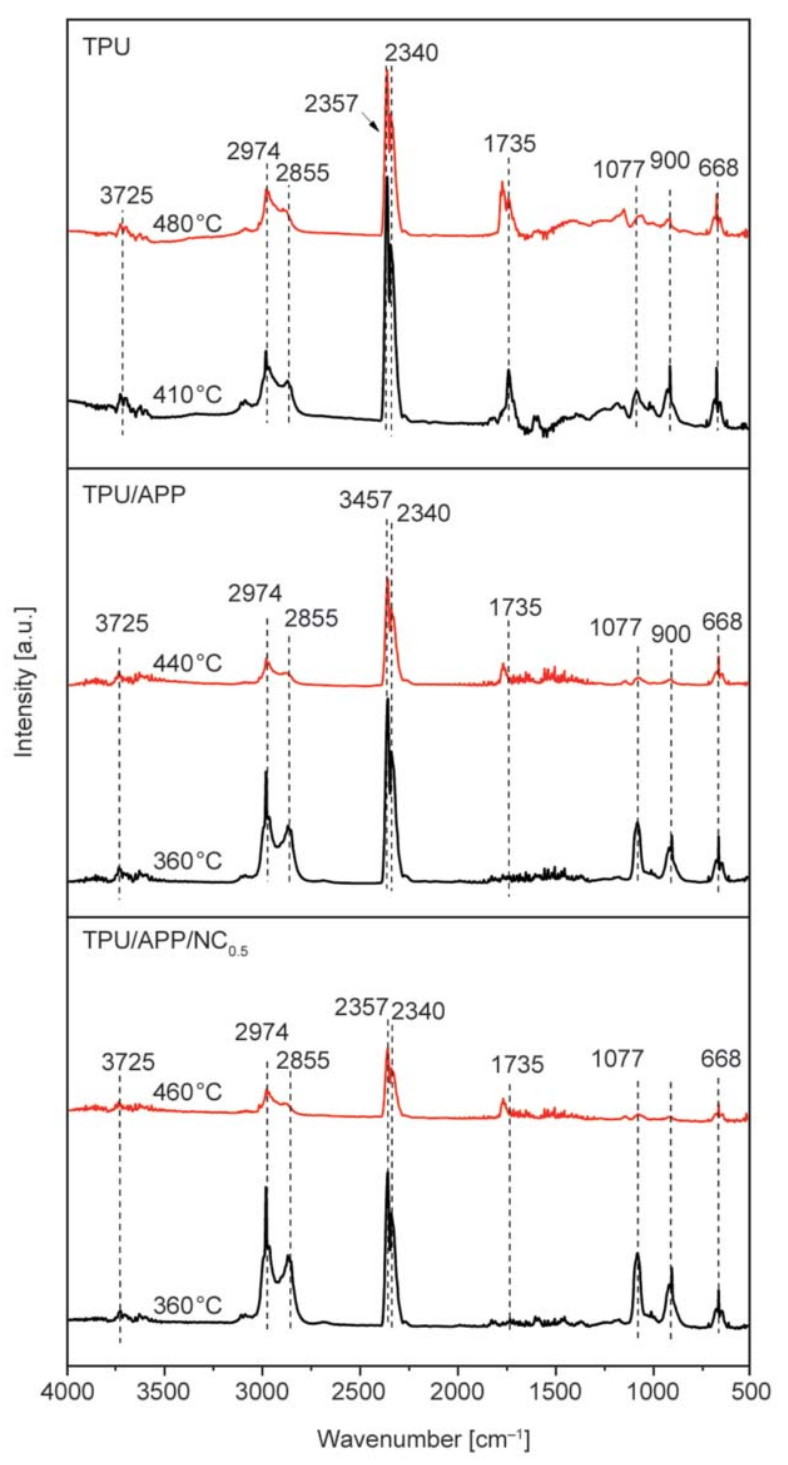

Figure 6. TG-IR spectra of pyrolysis products at maximum decomposition rate of TPU composites.

$-\mathrm{NCO}\left(2340 \mathrm{~cm}^{-1}\right), \mathrm{C}=\mathrm{O}\left(1735 \mathrm{~cm}^{-1}\right), \mathrm{C}-\mathrm{O}-\mathrm{C}$ $\left(1077 \mathrm{~cm}^{-1}\right), \mathrm{NH}_{3}\left(900 \mathrm{~cm}^{-1}\right)$ were showed clearly in Figure 6 [4, 5, 30, 33, 43-45]. Compare with TPU and TPU/APP, the bands of $\mathrm{CO}_{2}$ and -NCO were decreased for TPU/APP/NC composites, which indicated the combination of APP and NC possibly changed the decomposition process of TPU. In addition, the ester group and HCN were not visible in Figure 6, which were located in the bands of 1148 and $722 \mathrm{~cm}^{-1}$, respectively [46]. It is very interesting that there was almost no $\mathrm{NH}_{3}$ detected in this experiment. The reason is that $\mathrm{NH}_{3}$ decomposed from APP can react with the compounds containing $-\mathrm{NCO}$ from the degradation of TPU.

Gas chromatography/mass spectrometry (GC-Ms) was used to analyze the gas products that formed during the thermal decomposition of TPU composites. 


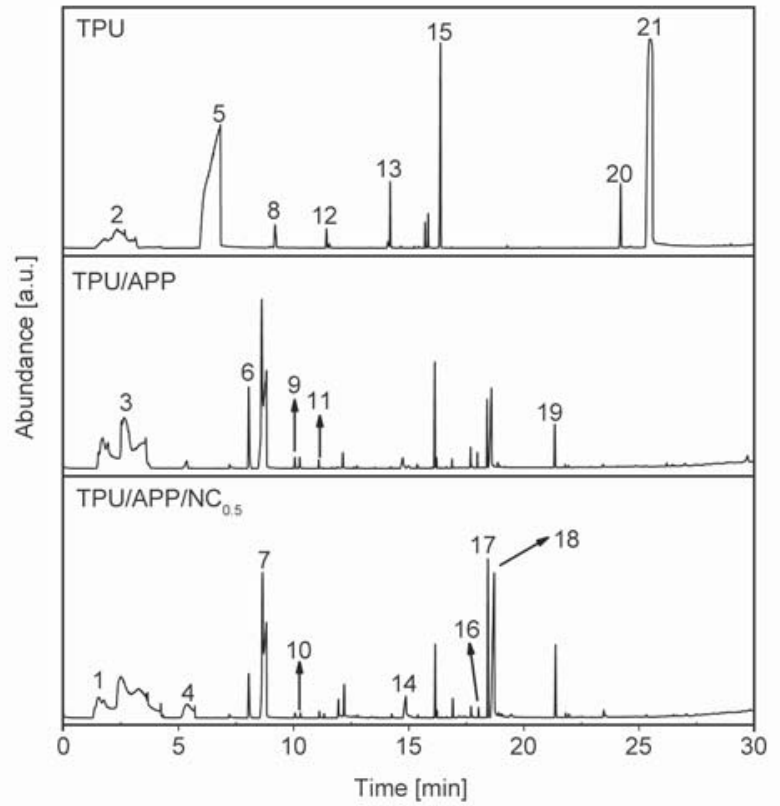

Figure 7. GC-Ms analysis results of volatile production during TPU composites degradation at $350^{\circ} \mathrm{C}$.

The total ion chromatogram was shown in Figure 7 and Table 5. The gas products were formed by pyrolysis from TPU, TPU/APP, and TPU/APP/ $/ \mathrm{NC}_{0.5}$ at $350^{\circ} \mathrm{C}$. There were three main ways for the initial degradation of carbamate bonds. So, the pyrolysis products from TPU were divided into three categories $[47,48]$.

The first group included pentan-2-amine (peak 1), carbon dioxide (peak 2), butane-1,4-diol (peak 5), isocyanatobenzene (peak 6), aniline (peak 7), 1-ethyl-2isocyanatobenzene (peak 8), 1-isocyanato-4-methylbenzene (peak 9), p-toluidine (peak 10), 1-ethoxy-2isocyanatobenzene (peak 12), 2-isocyanato-1,3-diisopropylbenzene (peak 13), 1-isocyanato-3-(4-isocyanatobenzyl) benzene (peak 20), and bis (4-isocyanatophenyl) methane (peak 21), respectively. These

Table 5. Compounds identified from the thermal pyrolysis chromatogram of TPU composites.

\begin{tabular}{|c|c|c|}
\hline $\begin{array}{c}\text { Peak } \\
\text { number }\end{array}$ & Assigned structures & $\begin{array}{c}\text { Ret. } \\
\text { time }\end{array}$ \\
\hline 1 & \\
\hline 2 & \\
\hline 3 & \\
\hline
\end{tabular}

Table 5. Continuance.

(1)


peaks corresponded to the primary cleavage of urethane linkage and ester. The second group included tetrahydrofuran (peak 3), cyclohexanone (peak 4), oxacycloundecane-2,7-dione (peak 15), 7-methyl-1, 4dioxepan-5-one (peak 17), and 1,4-dioxocan-5-one (peak 18). These were reasonably attributed to the thermal degradation of polyether polyols, which can happen, as dehydration, hydrogen transfer and transesterification reaction. In the last group, olefin end groups included but-3-en-1-ol (peak 11), hept-6enoic acid (peak 14), and butane-1,4-diyldiacrylate (peak 19), respectively.

With the loading of APP and NC, the intensity of peak 20 and peak 21 disappeared for the TPU/APP and TPU/APP/NC samples, the bis (4-isocyanatophenyl) methane was stored as residual char instead of volatilized, which reduced the smoke or flammable gas. This result meant that the decomposition process of TPU had been changed by the NC and APP, which corresponded with the results of CCT. During the combustion process of TPU composites, the surface of the char residue layer effectively kept the inside matrix from further decomposition.

\subsection{Possible flame retardant mechanism}

Based on the results of CCT, TG, SEM, XPS, LRS and XRD, the possible flame retardant mechanism of TPU/APP/NC composites was shown in Figure 8. The decomposition products of TPU mainly contained bis (4-isocyanatophenyl)methane and other small molecular products. NC mainly played an important role in the condensed phase. The decomposition process of TPU/APP/NC composites was changed by both NC and APP. APP was decomposed into polyphosphoric acid, and $\mathrm{NC}$ was decomposed into $\mathrm{NiO}$ and $\mathrm{Ni}$. The bis(4-isocyanatophenyl)methane was combined with polyphosphoric acid as well as $\mathrm{NiO}$ and $\mathrm{Ni}$, which remained in the char residues to form a condensed phase. $\mathrm{NiO}$ and $\mathrm{Ni}$ promoted the formation of a protective char residue layer on the surface of the TPU/APP/NC composites. The network structure of the char residue of TPU/APP/ $\mathrm{NC}_{0.5}$ was more compact and even, resulting in good flame retardant efficiency and smoke suppression properties.

\section{Conclusions}

This paper presented a new method to improve the flame retardant efficiency of TPU. NC was decomposed into $\mathrm{NiO}$ and $\mathrm{Ni}$, catalyzing the carbonization of TPU/APP composite and enhance the flame retardant efficiency. NC can reduce the thermal decomposition rate of TPU/APP/NC composites and obviously increased the char residues, resulting in high LOI value and UL-94 rating, good fire safety performance

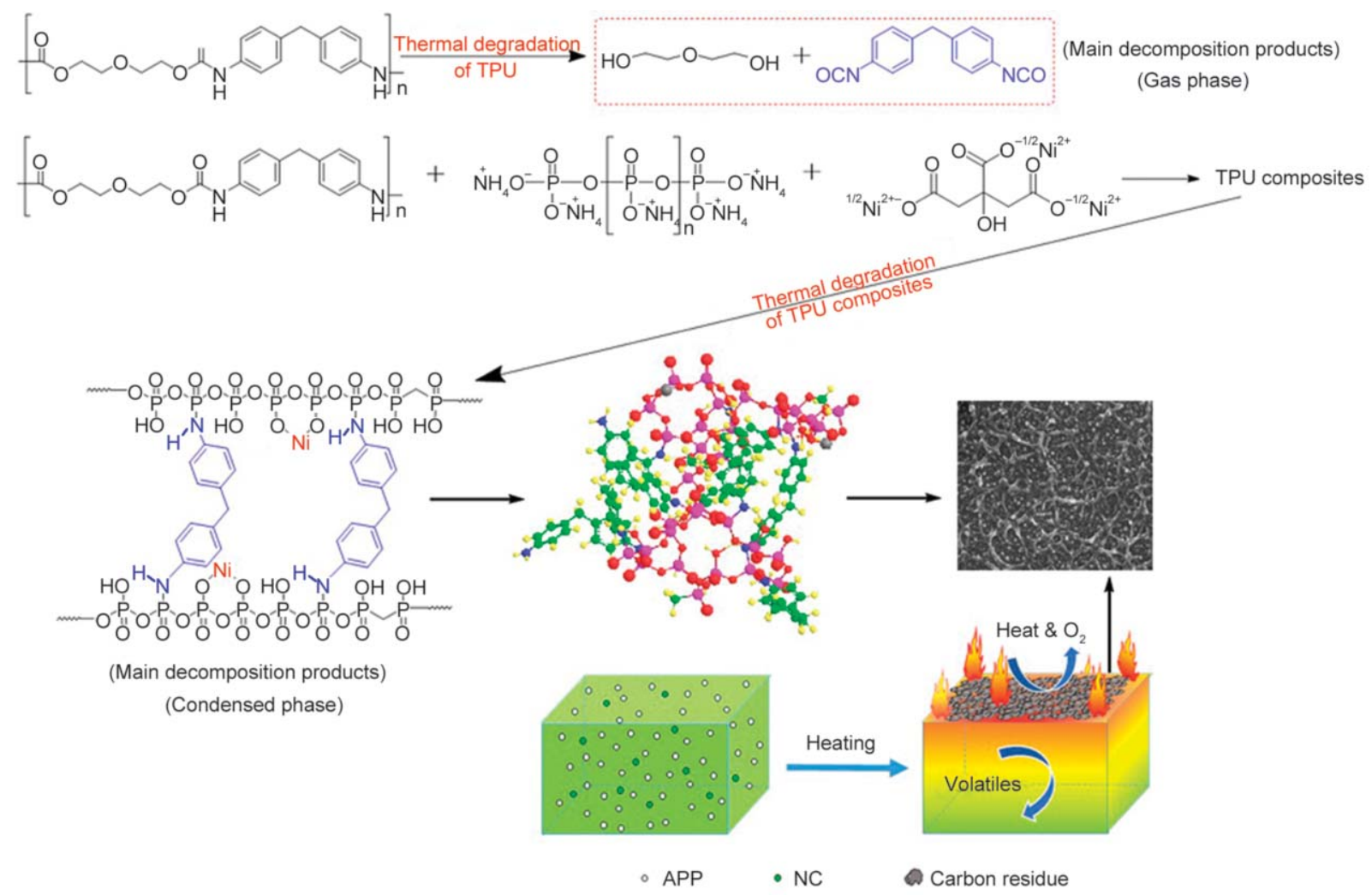

Figure 8. Possible flame retardant mechanism of TPU composites. 
with low production $\mathrm{CO}$ in the combustion process. The dense network structure of char residue with a high expansion degree effectively prevented the release of combustible gas smoke precursors, thus excellent flame retardancy was obtained. Overall, the combination of NC and APP had been proved to be a promising flame retardant system for TPU.

\section{Acknowledgements}

The authors gratefully acknowledge the National Natural Science Foundation of China (No. 51776101), the Project of the State Administration of Work Safety (Shandong-00392017AQ), and Shandong Provincial Natural Science Foundation of China (ZR2019MEE114).

\section{References}

[1] Shi Y., Fu L., Chen X., Guo J., Yang F., Wang J., Zheng Y., Hu Y.: Hypophosphite/graphitic carbon nitride hybrids: Preparation and flame-retardant application in thermoplastic polyurethane. Nanomaterials, 259, 259/1259/13 (2017).

https://doi.org/10.3390/nano7090259

[2] Shi Y., Yu B., Zhou K., Yuen R. K. K., Gui Z., Hu Y., Jiang S.: Novel $\mathrm{CuCo}_{2} \mathrm{O}_{4} /$ graphitic carbon nitride nanohybrids: Highly effective catalysts for reducing $\mathrm{CO}$ generation and fire hazards of thermoplastic polyurethane nanocomposites. Journal of Hazardous Materials, 293, 87-96 (2015). https://doi.org/10.1016/j.jhazmat.2015.03.041

[3] Yu B., Tawiah B., Wang L-Q., Yuen A. C. Y., Zhang Z-C., Shen L-L., Lin B., Fei B., Yang W., Li A., Zhu S-E., Hu E-Z., Lu H-D., Yeoh G. H.: Interface decoration of exfoliated MXene ultra-thin nanosheets for fire and smoke suppressions of thermoplastic polyurethane elastomer. Journal of Hazardous Materials, 374, 110-119 (2019). https://doi.org/10.1016/j.jhazmat.2019.04.026

[4] Wang J., Ma C., Mu X., Cai W., Liu L., Zhou X., Hu W., $\mathrm{Hu}$ Y.: Construction of multifunctional $\mathrm{MoSe}_{2}$ hybrid towards the simultaneous improvements in fire safety and mechanical property of polymer. Journal of Hazardous materials, 352, 36-46 (2018).

https://doi.org/10.1016/j.jhazmat.2018.03.003

[5] Pan Y-T., Castillo-Rodríguez M., Wang D-Y.: Mesoporous metal oxide/pyrophosphate hybrid originated from reutilization of water treatment resin as a novel fire hazard suppressant. Materials Chemistry and Physics, 203, 49-57 (2018).

https://doi.org/10.1016/j.matchemphys.2017.09.040

[6] Guler T., Tayfun U., Bayramli E., Dogan M.: Effect of expandable graphite on flame retardant, thermal and mechanical properties of thermoplastic polyurethane composites filled with huntite\&hydromagnesite mineral. Thermochimica Acta, 647, 70-80 (2017).

https://doi.org/10.1016/j.tca.2016.12.001
[7] Cai W., Feng X., Wang B., Hu W., Yuan B., Hong N., Hu Y.: A novel strategy to simultaneously electrochemically prepare and functionalize graphene with a multifunctional flame retardant. Chemical Engineering Journal, 316, 514-524 (2017).

https://doi.org/10.1016/j.cej.2017.01.017

[8] Xu Y-J., Shi X-H., Lu J-H., Qi M., Guo D-M., Chen L., Wang Y-Z.: Novel phosphorus-containing imidazolium as hardener for epoxy resin aiming at controllable latent curing behavior and flame retardancy. Composites Part B: Engineering, 184, 107673/1-107673/10 (2020). https://doi.org/10.1016/j.compositesb.2019.107673

[9] Zhang Y., Wang B., Yuan B., Yuan Y., Liew K. M., Song L., Hu Y.: Preparation of large-size reduced graphene oxide-wrapped ammonium polyphosphate and its enhancement of the mechanical and flame retardant properties of thermoplastic polyurethane. Industrial and Engineering Chemistry Research, 56, 7468-7477 (2017). https://doi.org/10.1021/acs.iecr.7b01235

[10] Chen M., Xu Y., Chen X., Ma Y., He W., Yu J., Zhang Z.: Thermal stability and combustion behavior of flameretardant polypropylene with thermoplastic polyurethane-microencapsulated ammonium polyphosphate. High Performance Polymers, 26, 445-454 (2014). https://doi.org/10.1177/0954008313517910

[11] Zhu M., Zhang Y., Sheng H., Wang B., Hu Y.: Effect carbon black microencapsulated ammonium polyphosphate on the flame retardancy and mechanical properties of polyurethane composites. Polymer-Plastics Technology and Materials, 59, 83-94 (2019). https://doi.org/10.1080/25740881.2019.1625384

[12] Chen X., Jiang Y., Liu J., Jiao C., Qian Y., Li S.: Smoke suppression properties of fumed silica on flame-retardant thermoplastic polyurethane based on ammonium polyphosphate. Journal of Thermal Analysis and Calorimetry, 120, 1493-1501 (2015). https://doi.org/10.1007/s10973-015-4424-4

[13] Zhao K., Xu W., Song L., Wang B., Feng H., Hu Y.: Synergistic effects between boron phosphate and microencapsulated ammonium polyphosphate in flameretardant thermoplastic polyurethane composites. Polymers for Advanced Technologies, 23, 894-900 (2012). https://doi.org/10.1002/pat.1985

[14] Wang H., Qiao H., Guo J., Sun J., Li H., Zhang S., Gu X.: Preparation of cobalt-based metal organic framework and its application as synergistic flame retardant in thermoplastic polyurethane (TPU). Composites Part B: Engineering, 182, 107498/1-107498/11 (2020). https://doi.org/10.1016/j.compositesb.2019.107498

[15] Wang J., Yuan B., Cai W., Qiu S., Tai Q., Yang H., Hu Y.: Facile design of transition metal based organophosphorus hybrids towards the flame retardancy reinforcement and toxic effluent elimination of polystyrene. Materials Chemistry and Physics, 214, 209-220 (2018). https://doi.org/10.1016/j.matchemphys.2018.04.100 
[16] Wu H., Zeng B., Chen J., Wu T., Li Y., Liu Y., Dai L.: An intramolecular hybrid of metal polyhedral oligomeric silsesquioxanes with special titanium-embedded cage structure and flame retardant functionality. Chemical Engineering Journal, 374, 1304-1316 (2019). https://doi.org/10.1016/j.cej.2019.06.027

[17] Morgan A. B.: A review of transition metal-based flame retardants: Transition metal oxide/salts, and complexes. in 'Fire and polymers V'(eds.: Wilkie C. A., Morgan A. B., Nelson G. L.) American Chemical Society, Washington, Vol 1013, 312-328 (2009). https://doi.org/10.1021/bk-2009-1013.ch019

[18] Ramgobin A., Fontaine G., Penverne C., Bourbigot S.: Thermal stability and fire properties of salen and metallosalens as fire retardants in thermoplastic polyurethane (TPU). Materials, 665, 665/1-665/18 (2017). https://doi.org/10.3390/ma10060665

[19] Shan X., Zhang P., Song L., Hu Y., Lo S.: Compound of nickel phosphate with $\mathrm{Ni}(\mathrm{OH})\left(\mathrm{PO}_{4}\right)_{2}-$ layers and synergistic application with intumescent flame retardants in thermoplastic polyurethane elastomer. Industrial and Engineering Chemistry Research, 50, 72017209 (2011). https://doi.org/10.1021/ie2001555

[20] Wei W-C., Deng C., Huang S-C., Wei Y-X., Wang Y-Z.: Nickel-schiff base decorated graphene for simultaneously enhancing the electroconductivity, fire resistance, and mechanical properties of a polyurethane elastomer. Journal of Materials Chemistry A, 6, 8643-8654 (2018). https://doi.org/10.1039/c8ta01287c

[21] Zhang Y., Cui J., Wang L., Liu H., Yang B., Guo J., Mu B., Tian L.: Phosphorus-containing salen-metal complexes investigated for enhancing the fire safety of thermoplastic polyurethane (TPU). Polymers for Advanced Technologies, 31, 1150-1163 (2020).

https://doi.org/10.1002/pat.4849

[22] He S., Wu H., Yu W., Mo L., Lou H., Zheng X.: Combination of $\mathrm{CO}_{2}$ reforming and partial oxidation of methane to produce syngas over $\mathrm{Ni} / \mathrm{SiO}_{2}$ and $\mathrm{Ni}-\mathrm{Al}_{2} \mathrm{O}_{3} /$ $\mathrm{SiO}_{2}$ catalysts with different precursors. International Journal of Hydrogen Energy, 34, 839-843 (2009). https://doi.org/10.1016/j.ijhydene.2008.10.072

[23] Abu-Zied B. M., Asiri A. M.: An investigation of the thermal decomposition of nickel citrate as a precursor for Ni-NiO composite nanoparticles. Thermochimica Acta, 649, 54-62 (2017).

https://doi.org/10.1016/j.tca.2017.01.003

[24] Calafat Á., Sánchez N.: Production of carbon nanotubes through combination of catalyst reduction and methane decomposition over $\mathrm{Fe}-\mathrm{Ni} / \mathrm{ZrO}_{2}$ catalysts prepared by the citrate method. Applied Catalysis A: General, 528, 14-23 (2016).

https://doi.org/10.1016/j.apcata.2016.09.012
[25] Shi Y., Yu B., Zheng Y., Yang J., Duan Z., Hu Y.: Design of reduced graphene oxide decorated with DOPO-phosphanomidate for enhanced fire safety of epoxy resin. Journal of Colloid and Interface Science, 521, 160-171 (2018).

https://doi.org/10.1016/j.jcis.2018.02.054

[26] Shi Y., Yu B., Duan L., Gui Z., Wang B., Hu Y., Yuen R. K. K.: Graphitic carbon nitride/phosphorus-rich aluminum phosphinates hybrids as smoke suppressants and flame retardants for polystyrene. Journal of Hazardous Materials, 332, 87-96 (2017). https://doi.org/10.1016/j.jhazmat.2017.03.006

[27] Yu B., Xing W., Guo W., Qiu S., Wang X., Lo S., Hu Y.: Thermal exfoliation of hexagonal boron nitride for effective enhancements on thermal stability, flame retardancy and smoke suppression of epoxy resin nanocomposites via sol-gel process. Journal of Materials Chemistry $\mathrm{A}, 4,7330-7340$ (2016).

https://doi.org/10.1039/c6ta01565d

[28] Zhao X-L., Chen C-K., Chen X-L.: Effects of carbon fibers on the flammability and smoke emission characteristics of halogen-free thermoplastic polyurethane/ ammonium polyphosphate. Journal of Materials Science, 51, 3762-3771 (2016).

https://doi.org/10.1007/s10853-015-9694-5

[29] Chen C., Zhao X., Shi C., Chen J.: Synergistic effect between carbon nanoparticle and intumescent flame retardant on flammability and smoke suppression of copolymer thermoplastic polyurethane. Journal of Materials Science, 53, 6053-6064 (2018).

https://doi.org/10.1007/s10853-017-1970-0

[30] Liu L., Zhao X., Ma C., Chen X., Li S., Jiao C.: Smoke suppression properties of carbon black on flame retardant thermoplastic polyurethane based on ammonium polyphosphate. Journal of Thermal Analysis and Calorimetry, 126, 1821-1830 (2016). https://doi.org/10.1007/s10973-016-5815-x

[31] Chen X., Jiang Y., Jiao C.: Smoke suppression properties of ferrite yellow on flame retardant thermoplastic polyurethane based on ammonium polyphosphate. Journal of Hazardous Materials, 266, 114-121 (2014). https://doi.org/10.1016/j.jhazmat.2013.12.025

[32] Yuan B., Sun Y., Chen X., Shi Y., Dai H., He S.: Poorly-/well-dispersed graphene: Abnormal influence on flammability and fire behavior of intumescent flame retardant. Composites Part A: Applied Science and Manufacturing, 109, 345-354 (2018).

https://doi.org/10.1016/j.compositesa.2018.03.022

[33] Zhang B., Liu H., Han J.: Retracted: Aluminum phosphate microcapsule flame retardants for flexible polyurethane foams. Journal of Physics and Chemistry of Solids, 115, 199-207 (2018). https://doi.org/10.1016/j.jpcs.2017.12.048 
[34] Yuan B., Hu Y., Chen X., Shi Y., Niu Y., Zhang Y., He S., Dai H.: Dual modification of graphene by polymeric flame retardant and $\mathrm{Ni}(\mathrm{OH})_{2}$ nanosheets for improving flame retardancy of polypropylene. Composites Part A: Applied Science and Manufacturing, 100, 106-117 (2017).

https://doi.org/10.1016/j.compositesa.2017.04.012

[35] Zhou K., Liu C., Gao R.: Polyaniline: A novel bridge to reduce the fire hazards of epoxy composites. Composites Part A: Applied Science and Manufacturing, 112, 432-443 (2018). https://doi.org/10.1016/j.compositesa.2018.06.031

[36] Zhou K., Tang G., Gao R., Jiang S.: In situ growth of OD silica nanospheres on 2D molybdenum disulfide nanosheets: Towards reducing fire hazards of epoxy resin. Journal of Hazardous Materials, 344, 1078-1089 (2018). https://doi.org/10.1016/j.jhazmat.2017.11.059

[37] Zhou K., Gao R., Qian X.: Self-assembly of exfoliated molybdenum disulfide $\left(\mathrm{MoS}_{2}\right)$ nanosheets and layered double hydroxide (LDH): Towards reducing fire hazards of epoxy. Journal of Hazardous Materials, 338, 343 355 (2017).

https://doi.org/10.1016/j.jhazmat.2017.05.046

[38] Zhao S., Yin J., Zhou K., Cheng Y., Yu B.: In situ fabrication of molybdenum disulfide based nanohybrids for reducing fire hazards of epoxy. Composites Part A: Applied Science and Manufacturing, 122, 77-84 (2019). https://doi.org/10.1016/j.compositesa.2019.04.023

[39] Rao W-H., Xu H-X., Xu Y-J., Qi M., Liao W., Xu S., Wang Y-Z.: Persistently flame-retardant flexible polyurethane foams by a novel phosphorus-containing polyol. Chemical Engineering Journal, 343, 198-206 (2018). https://doi.org/10.1016/j.cej.2018.03.013

[40] Zhang L., Chen S., Pan Y-T., Zhang S., Nie S., Wei P., Zhang X., Wang R., Wang D-Y.: Nickel metal-organic framework derived hierarchically mesoporous nickel phosphate toward smoke suppression and mechanical enhancement of intumescent flame retardant wood fiber/ poly(lactic acid) composites. ACS Sustainable Chemistry and Engineering, 7, 9272-9280 (2019).

https://doi.org/10.1021/acssuschemeng.9b00174
[41] Chen M., Tang M., Ma Y., Chen X., Qin J., He W., Zhang Z.: Influence of polyamide 6 as a charring agent on the flame retardancy, thermal, and mechanical properties of polypropylene composites. Polymer Engineering and Science, 55, 1355-1360 (2015). https://doi.org/10.1002/pen.24075

[42] Song P., Dai J., Chen G., Yu Y., Fang Z., Lei W., Fu S., Wang H., Chen Z-G.: Bioinspired design of strong, tough, and thermally stable polymeric materials via nanoconfinement. ACS Nano, 12, 9266-9278 (2018). https://doi.org/10.1021/acsnano.8b04002

[43] Wang B., Sheng H., Shi Y., Song L., Zhang Y., Hu Y., $\mathrm{Hu}$ W.: The influence of zinc hydroxystannate on reducing toxic gases $(\mathrm{CO}, \mathrm{NOx}$ and $\mathrm{HCN})$ generation and fire hazards of thermoplastic polyurethane composites. Journal of Hazardous Materials, 314, 260-269 (2016). https://doi.org/10.1016/j.jhazmat.2016.04.029

[44] Pallmann J., Ren Y-L., Mahltig B., Huo T-G.: Phosphorylated sodium alginate/APP/DPER intumescent flame retardant used for polypropylene. Journal of Applied Polymer Science, 136, 47794/1-47794/10 (2019). https://doi.org/10.1002/app.47794

[45] Shi Y., Wang L., Fu L., Liu C., Yu B., Yang F., Hu Y.: Sodium alginate-templated synthesis of $\mathrm{g}-\mathrm{C}_{3} \mathrm{~N}_{4} /$ carbon spheres/Cu ternary nanohybrids for fire safety application. Journal of Colloid and Interface Science, 539, 1-10 (2019). https://doi.org/10.1016/j.jcis.2018.12.051

[46] Wang J., Yuan B., Mu X., Wang W., Hu W., Hu Y.: Novel incorporation of mesoporous $\mathrm{NiCo}_{2} \mathrm{O}_{4}$ into thermoplastic polyurethane for enhancing its fire safety. RSC Advances, 6, 109620-109632 (2016). https://doi.org/10.1039/c6ra24264b

[47] Zhang Y., Xia Z., Huang H., Chen H.: A degradation study of waterborne polyurethane based on TDI. Polymer Testing, 28, 264-269 (2009).

https://doi.org/10.1016/j.polymertesting.2008.12.011

[48] Zhang Y., Xia Z., Huang H., Chen H.: Thermal degradation of polyurethane based on IPDI. Journal of Analytical and Applied Pyrolysis, 84, 89-94 (2009). https://doi.org/10.1016/j.jaap.2008.11.008 